\title{
BMJ Open Cross-sectional survey of attitudes and beliefs about back pain in New Zealand
}

\author{
Ben Darlow, ${ }^{1}$ Meredith Perry, ${ }^{2}$ James Stanley, ${ }^{3}$ Fiona Mathieson, ${ }^{4}$ Markus Melloh, ${ }^{5}$ \\ G David Baxter, ${ }^{2}$ Anthony Dowell ${ }^{1}$
}

To cite: Darlow B, Perry M, Stanley J, et al. Crosssectional survey of attitudes and beliefs about back pain in New Zealand. BMJ Open 2014:4:e004725 doi:10.1136/bmjopen-2013004725

- Prepublication history and additional material is available. To view please visit the journal (http://dx.doi.org/ 10.1136/bmjopen-2013004725)

Received 19 December 2013 Revised 12 March 2014 Accepted 2 May 2014

\section{SLinked}

- http://dx.doi.org/10.1136/ bmjopen-2014-005251

CrossMark

For numbered affiliations see end of article.

Correspondence to

Ben Darlow;

ben.darlow@otago.ac.nz.

\section{ABSTRACT}

Objectives: To explore the prevalence of attitudes and beliefs about back pain in New Zealand and compare certain beliefs based on back pain history or health professional exposure.

Design: Population-based cross-sectional survey.

Setting: Postal survey.

Participants: New Zealand residents and citizens aged 18 years and above. 1000 participants were randomly selected from the New Zealand Electoral Roll. Participants listed on the Electoral Roll with an overseas postal address were excluded. 602 valid responses were received.

Measures: Attitudes and beliefs about back pain were measured with the Back Pain Attitudes Questionnaire (Back-PAQ). The interaction between attitudes and beliefs and (1) back pain experience and (2) health professional exposure was investigated.

Results: The lifetime prevalence of back pain was reported as $87 \%(95 \% \mathrm{Cl} 84 \%$ to $90 \%)$, and the point prevalence as $27 \%$ (95\% Cl $24 \%$ to $31 \%$ ). Negative views about the back and back pain were prevalent, in particular the need to protect the back to prevent injury. People with current back pain had more negative overall scores, particularly related to back pain prognosis. There was uncertainty about links between pain and injury and appropriate physical activity levels during an episode of back pain. Respondents had more positive views about activity if they had consulted a health professional about back pain. The beliefs of New Zealanders appeared to be broadly similar to those of other Western populations.

Conclusions: A large proportion of respondents believed that they needed to protect their back to prevent injury; we theorise that this belief may result in reduced confidence to use the back and contribute to fear avoidance. Uncertainty regarding what is a safe level of activity during an episode of back pain may limit participation. People experiencing back pain may benefit from more targeted information about the positive prognosis. The provision of clear guidance about levels of activity may enable confident participation in an active recovery.

\section{INTRODUCTION}

Low back pain (LBP) is a common health problem worldwide, ${ }^{1}$ and is one of the

\section{Strengths and limitations of this study}

- The attitudes and beliefs about the back pain of 1000 randomly selected New Zealanders were assessed using a novel survey instrument.

- A $60 \%$ response rate was achieved and the sample appeared to be representative of the target population.

- The lifetime prevalence of back pain among respondents was $87 \%$ ( $95 \% \mathrm{Cl} 84 \%$ to $90 \%$ ); this figure, although similar to previous studies, may be inflated as people who have not experienced back pain may be less likely to respond to a survey about back pain.

- The limited number of respondents who had not experienced back pain generally resulted in inadequate power to demonstrate differences between their beliefs and those of people who had experienced back pain.

leading causes of health loss in New Zealand (NZ). ${ }^{2}$ Costs associated with LBP represent a major financial burden in NZ and internationally. ${ }^{3-7}$ Although most episodes of LBP are self-limiting and not related to serious disease, ${ }^{8}$ a significant proportion of people are not fully recovered 12 months after onset. $^{9}$

Attitudes and beliefs are important factors in the development of back pain and related disability. ${ }^{10-12}$ Fear avoidance beliefs and low recovery expectations are independently associated with poor outcomes, including delayed return to work, activity limitation and pain persistence. ${ }^{13} 14$ Previous surveys have found that attitudes and beliefs inconsistent with current research evidence were prevalent in Australia, ${ }^{15}$ Belgium, ${ }^{16}$ Canada, ${ }^{17}$ Norway $^{18}$ and the UK. ${ }^{19}$

Attempts have been made to change beliefs at a population level in order to improve back pain outcomes, but these have had mixed, and largely unsatisfactory, results. ${ }^{17} 2021$ Interventions to modify attitudes and beliefs about back pain must not only be developed with knowledge of any unhelpful beliefs which are prevalent, but 
also the basis on which these beliefs are constructed. Recent qualitative research has indicated that fear avoidance beliefs may be based on an underlying idea that the back is vulnerable to injury and needs to be protected, and that activity participation may be limited by risks perceived as associated with activity. ${ }^{22}$ The Back Pain Attitudes Questionnaire (Back-PAQ) was developed following these interviews with people experiencing acute and chronic LBP $^{23}$ It aims to assess beliefs which underlie common attitudes about back pain.

New Zealanders may have different beliefs to those found overseas. NZ has a unique universal accident compensation scheme. The Accident Compensation Corporation (ACC) scheme has a focus on public education and has previously run comprehensive multimedia education campaigns relating to back pain prevention and management. It is therefore important that NZ beliefs are investigated to establish a current baseline and identify which beliefs (if any) should be targeted with future NZ campaigns.

This study aimed to (1) explore the prevalence of beliefs about back pain in NZ and (2) compare certain beliefs based on back pain history or health professional exposure.

\section{METHODS}

\section{Participants}

NZ citizens or residents aged 18 years and over were sampled via the NZ Electoral Roll. It is a legal requirement for all New Zealanders aged 18 years and over to be listed on the Electoral Roll. The Electoral Commission estimate that over $90 \%$ of eligible voters are enrolled. ${ }^{24}$ New Zealanders of Māori descent can opt to be on the General Electoral Roll or the Māori Electoral Roll. People who were listed on the Electoral Roll but had overseas postal addresses were excluded from this survey.

The sample size calculation indicated that $400 \mathrm{com}-$ plete responses were required (http://www.openepi. com, accessed 30 May 2012) to achieve an estimation accuracy of $\pm 5 \%$ for prevalence data. The likely response rate was estimated to be $40 \%,{ }^{25}$ so 1000 respondents were randomly selected from the Electoral Roll. The random sample was generated by using the 'random() function' in the PostgreSQL database management system V.9.1.4 (http://postgresql.org/; The PostgreSQL Global Development Group, California, USA). Māori and non-Māori respondents were selected in proportion with the overall NZ population to correct for underrepresentation of Māori on the Electoral Roll. ${ }^{26}{ }^{27}$ At the time of the survey, $15 \%$ of the NZ population were estimated to be Māori. ${ }^{28}$ Accordingly, 150 names were randomly selected from the Māori Electoral Roll, and the remaining 850 were randomly selected from the General Electoral Roll. Although some Māori choose to be on the General Electoral Roll, the degree of oversampling this produced was considered to be appropriate given that Māori are less likely to respond to postal surveys. ${ }^{29}$ Each respondent was allocated a random survey code.

\section{Survey instrument}

The Back-PAQ was used to collect data. The development of the Back-PAQ has been described elsewhere. ${ }^{23}$ The Back-PAQ contains 34 items scored on a five-point Likert scale, with response options ranging from 'False' to 'True'. The items were derived from the analysis of qualitative interviews with people experiencing acute and chronic back pain, ${ }^{22}$ as well as items used in previous surveys of beliefs. ${ }^{16-19}{ }^{30}$ For items scored in a forward direction, higher scores ('True' responses) indicate beliefs unhelpful for recovery from back pain. The questionnaire contains 11 reverse scored items $(1,2,3,15,16,17,27,28,29,30,31)$.

Gender, age and ethnicity questions were included to allow sample description. Questions related to back pain experience ('never had back pain', 'had back pain in the past', 'currently have back pain') and healthcare professional (HCP) exposure ("never seen a health professional for back pain', 'seen a health professional for back pain') were included to allow subgroup comparisons.

\section{Data collection}

Data were collected via postal survey. In September 2012, all 1000 respondents were posted an invitation to participate and a survey, together with a postage-paid return-addressed envelope. Respondents were offered postal and online (http://www.surveymonkey.com) response options. Two weeks later, a reminder letter with a second copy of the survey was posted to those from whom responses had not been received. ${ }^{31}$ Two weeks later, a reminder postcard was sent to those from whom responses had not been received. Eight weeks later, a final reminder letter and third copy of the survey was sent to those from whom responses had not been received.

Respondents who replied within 3 weeks were offered the chance to enter a major prize draw (two prizes of approximate value NZ\$900). ${ }^{32}$ Respondents who replied within 10 weeks were offered the chance to enter a minor prize draw (five prizes of value NZ $\$ 100$ ). A chocolate bar was included with the third (final) distribution of the survey. Data collection was completed on 4 March 2013; surveys which were returned after this date $(n=1)$ were not included in the results.

\section{Statistical analysis}

All analyses were conducted using SPSS V.20.0 for Windows software (SPSS, Inc, Chicago, Illinois, USA). Descriptive statistics were calculated for item scores and total scale scores (reversed item scores were corrected before total scale score calculation; a minimum of 17 valid responses was required). Frequency results are presented with 'False' and 'Possibly False' categories 
combined, and 'True' and 'Possibly True' categories combined. An $\alpha$ level of 0.05 was used to judge significance for a priori hypothesis tests. CIs for prevalence data were calculated using Fisher's exact method. ${ }^{33}$ Missing data were handled by conducting complete case analysis. The number of cases included for each analysis is reported within the results. A sensitivity analysis was conducted for back pain prevalence assuming that all non-respondents did not have back pain. A biostatistician (JS) oversaw the analyses.

Differences in response means for preselected items, according to back pain experience (items $1,6,11,22,28,32,33,34$ ) and HCP exposure (items $3,4,5,7,8,10,13,22,25,27)$, were calculated using one-way analysis of variance (ANOVA). Only those who reported having experienced back pain were included in the HCP exposure analysis. Post hoc analysis using Tukey's honestly significant difference test was performed following significant ANOVA results to ascertain which group means for the three categories of back pain experience were significantly different from each other. Although some data were not normally distributed, due to the sample size, the distributional assumptions on which the ANOVA is based were considered to have been met (central limit theorem). CIs for differences were based on post hoc tests: Tukey's test for differences according to the back pain experience group and t-distribution-based CIs for differences according to HCP exposure. Linear regression models were used to examine the effect of adjusting main effects (back pain experience, HCP exposure) for covariates that might differ by these groups (age, sex and HCP exposure when analysing by back pain experience).

One-way ANOVA with age as the dependent variable was used to examine the relationship between responses to item 5 ('Lifting without bending your knees is not safe for your back') and age.

\section{RESULTS}

In all, 602 valid responses were received between 7 September 2012 and 14 February 2013, a response rate of $60 \%$. One response was excluded because the respondent reported being 17 years old and therefore ineligible (one must be 18 to be on the Electoral Roll; this indicated either that he was not the intended recipient or that he had provided incorrect information on the returned survey). Two respondents only completed demographic items; they were included in the study as they contributed to prevalence data on back pain and HCP usage; however, they did not contribute to item or total scores. Fifty-one of the non-response survey packs were returned unopened because the respondent was no longer at the address listed on the Electoral Roll. The characteristics of respondents are shown in table 1 . All proportions presented have a maximal margin of error of $\pm 4 \%$ due to the sample size of 602 . No item had more than $2.3 \%$ missing data. The number of surveys

\begin{tabular}{lc} 
Table 1 Respondent characteristics & \\
\hline Characteristic & $\mathbf{n}(\%)^{\star}$ \\
\hline Age (years; mean (range)) & $602(50.6(18-97))$ \\
Female & $331(55)$ \\
Male & $271(45)$ \\
Ethnicity $\dagger$ & \\
New Zealand European & $487(80.9)$ \\
Māori & $81(13.5)$ \\
Asian & $45(7.5)$ \\
Pacific & $20(3.3)$ \\
Middle East/Latin American & $6(1.0)$ \\
Other & $3(0.5)$ \\
Not stated & $11(1.8)$ \\
Back pain history & $76(12.6)$ \\
Never & $361(60.0)$ \\
Past & $164(27.2)$ \\
Current & $1(0.2)$ \\
Not stated & $210(34.9)$ \\
Healthcare professional use for back pain \\
Never seen \\
Have seen \\
Not stated & $389(64.6)$ \\
*Unless otherwise noted. & $3(0.5)$ \\
†Total equals more than 100\% as respondents were able to select \\
more than one category (39 respondents selected two ethnicity \\
categories, and 3 selected three). \\
\end{tabular}

with all items answered was comparable between people with no back pain experience $(88 \%)$, past back pain $(88 \%)$ and current back pain $(87 \%)$.

Lifetime prevalence of back pain among respondents $(\mathrm{n}=601)$ was reported as $87 \%$ (95\% CI $84 \%$ to $90 \%)$, and point prevalence as $27 \%$ (95\% CI $24 \%$ to $31 \%$ ). As a sensitivity analysis, if it were assumed that all nonrespondents did not have back pain, this would provide a minimum possible lifetime prevalence of 53\% (95\% CI $49 \%$ to $56 \%)$ and point prevalence of $16 \%$ (95\% CI $14 \%$ to $19 \%$ ).

\section{Item and scale responses}

Response means and proportions selecting 'True' or 'Possibly True' responses for individual items are shown in table 2. 'True' and 'Possibly True' responses have been combined to improve ease of interpretation. Proportions selecting each response for individual items are presented in online supplementary table S1. Although $76 \%$ of respondents believed that their back was one of the strongest parts of their body (item 1) and $78 \%$ thought that their back was well designed (item 2), $89 \%$ thought that their back was easy to injure (item 6 ) and $95 \%$ believed that they could injure their back if they were not careful (item 11); 403 (67\%) respondents selected 'True' or 'Possibly True' to items 1 and 6 (figure 1). In order to protect the back, 99\% thought that good posture was important (item 8), and $97 \%$ believed that they needed strong muscles (item 7). 
Table 2 Response means and frequency of True ('True' or 'Possibly True' responses) for individual Back Pain Attitudes Questionnaire (Back-PAQ) items

\begin{tabular}{|c|c|c|c|}
\hline Item & $\begin{array}{l}\text { Mean } \\
(\mathrm{SD})^{\star}\end{array}$ & $\begin{array}{l}\text { Percentage } \\
\text { True }(95 \% \text { Cl)† }\end{array}$ & $\mathbf{n}$ \\
\hline 1. Your back is one of the strongest parts of your body & $4.0(1.3)$ & $76.0(72.4$ to 79.4$)$ & 596 \\
\hline 2. Your back is well designed for the way you use it in daily life & $4.1(1.2)$ & 77.8 (74.2 to 81.1$)$ & 590 \\
\hline 3. Bending your back is good for it & $3.5(1.4)$ & 59.3 (55.2 to 63.3$)$ & 589 \\
\hline 4. Sitting is bad for your back & $2.9(1.4)$ & 42.7 (38.6 to 46.8$)$ & 588 \\
\hline 5. Lifting without bending your knees is not safe for your back & $4.7(0.9)$ & 93.5 (91.2 to 95.3$)$ & 598 \\
\hline 6. It is easy to injure your back & $4.5(0.9)$ & 89.3 (86.5 to 91.6$)$ & 597 \\
\hline 7. It is important to have strong muscles to support your back & $4.8(0.6)$ & 96.5 (94.7 to 97.8$)$ & 596 \\
\hline 8. Good posture is important to protect your back & $4.9(0.4)$ & $98.7(97.4$ to 99.4$)$ & 598 \\
\hline 9. If you overuse your back, it will wear out & $3.3(1.5)$ & 51.8 (47.8 to 55.9$)$ & 598 \\
\hline 10. If an activity or movement causes back pain, you should avoid it in the future & $3.5(1.4)$ & 58.9 (54.8 to 62.9$)$ & 594 \\
\hline 11. You could injure your back if you are not careful & $4.7(0.7)$ & $94.9(92.8$ to 96.6$)$ & 592 \\
\hline 12. You can injure your back and only become aware of the injury some time later & $4.3(1.1)$ & 83.9 (80.8 to 86.8$)$ & 598 \\
\hline 13. Back pain means that you have injured your back & $3.3(1.3)$ & 56.5 (52.4 to 60.5$)$ & 598 \\
\hline 14. A twinge in your back can be the first sign of a serious injury & $3.6(1.1)$ & 63.9 (59.9 to 67.7$)$ & 598 \\
\hline 15. Thoughts and feelings can influence the intensity of back pain & $3.5(1.4)$ & 58.2 (54.1 to 62.2$)$ & 596 \\
\hline 16. Stress in your life (financial, work, relationship) can make back pain worse & $3.6(1.4)$ & 63.6 (59.6 to 67.5$)$ & 596 \\
\hline $\begin{array}{l}\text { 17. When you have back pain, you can do things which increase your pain without } \\
\text { harming the back }\end{array}$ & $3.0(1.3)$ & 39.4 (35.5 to 43.5$)$ & 596 \\
\hline 18. Having back pain makes it difficult to enjoy life & $4.6(0.8)$ & 94.1 (91.9 to 95.9$)$ & 595 \\
\hline 19. It is worse to have pain in your back tha & $4.0(1.2)$ & 72.1 (68.3 to 75.7$)$ & 595 \\
\hline 20. It is hard to understand what back pain is like if you have never had it & $4.5(0.8)$ & 92.9 (90.5 to 94.8$)$ & 592 \\
\hline 21. If your back hurts, you should take it easy until the pain goes away & $3.7(1.3)$ & $69.3(65.4$ to 73.0$)$ & 590 \\
\hline 22. If you ignore back pain, you may cause damage to your back & $4.4(0.9)$ & 89.3 (86.5 to 91.7$)$ & 598 \\
\hline 23. It is important to see a health professional when you have back pain & $4.3(1.0)$ & 84.8 (81.7 to 87.6$)$ & 593 \\
\hline 24. To effectively treat back pain, you need to know exactly what is wrong & $4.4(1.0)$ & $86.2(83.2$ to 88.9$)$ & 594 \\
\hline 25. If you have back pain you should avoid exercise & $2.4(1.3)$ & $24.9(21.4$ to 28.6$)$ & 595 \\
\hline 26. When you have back pain the risks of vigorous exercise outweigh the benefits & $3.6(1.3)$ & 55.1 (51.0 to 59.2$)$ & 593 \\
\hline 27. If you have back pain you should try to stay active & $4.2(1.0)$ & 80.0 (76.6 to 83.1$)$ & 595 \\
\hline 28. Most back pain settles quickly, at least enough to get on with normal activities & $3.7(1.2)$ & 63.9 (59.9 to 67.8$)$ & 593 \\
\hline 29. Worrying about your back can delay recovery from back pain & $3.4(1.3)$ & 54.3 (50.2 to 58.3$)$ & 597 \\
\hline 30. Focusing on things other than the back helps you to recover from back pain & $3.4(1.3)$ & $55.5(51.4$ to 59.6$)$ & 596 \\
\hline 31. Expecting your back pain to get better helps you to recover from back pain & $3.3(1.4)$ & $52.4(48.3$ to 56.5$)$ & 595 \\
\hline 32. Once you have had back pain there is always a weakness & $3.3(1.3)$ & $51.8(47.7$ to 55.8$)$ & 597 \\
\hline 33. There is a high chance that an episode of back pain will not resolve & $3.2(1.3)$ & 43.5 (39.4 to 47.5$)$ & 596 \\
\hline 34. Once you have a back problem, there is not a lot you can do about it & $2.0(1.3)$ & $15.9(13.1$ to 19.1$)$ & 596 \\
\hline
\end{tabular}

${ }^{*} 1.0=$ ='False', 3.0='Unsure', 5.0='True'; these are raw scores which have not been adjusted for question direction.

†Combined 'True' and 'Possibly True' responses.

Furthermore, $94 \%$ of respondents believed that it was not safe to lift without bending the knees (item 5 ).

Most respondents (84\%) thought that they could injure their back and only become aware of the injury at a subsequent point in time (item 12); $64 \%$ thought a 'twinge' could be the first sign of a serious injury (item 14). $59 \%$ thought that if a movement causes pain, they should avoid it in the future (item 10), and 89\% thought that by ignoring pain they may damage their back (item 22). $52 \%$ believed that there is always a weakness after having back pain (23\% unsure; item 32).

Most respondents (94\%) thought that having back pain makes it difficult to enjoy life (item 18), and 93\% thought that it is hard to understand back pain if you have not had it yourself (item 20). A majority of respondents $(72 \%)$ considered it worse to have pain in the back than the limbs (item 19).
In order to manage back pain, $85 \%$ of respondents believed that it was important to see an HCP (item 23), and $86 \%$ believed that they needed to know exactly what was wrong (item 24). Staying active during an episode of back pain was supported by $80 \%$ (item 27); however, $69 \%$ also thought they should take it easy (item 21), 55\% thought the risks of vigorous exercise outweighed the benefits (26\% unsure; item 26) and 25\% believed exercise should be avoided (item 25). Many of the respondents who did not believe that exercise should be avoided also believed that the risks of vigorous exercise outweighed the benefits; 176 (29\%) respondents selected 'False' or 'Possibly False' to item 25 and 'True' or 'Possibly True' to item 26 (figure 2).

The mean Back-PAQ score was 3.39 (SD 0.37; 95\% CI 3.36 to $3.42 ; n=598 ; 4$ respondents provided insufficient valid responses); as this was greater than 3 , it demonstrated that unhelpful beliefs were on average more prevalent 
Figure 1 Scatter plot with density to display the correlation between item 1: 'Your back is one of the strongest parts of your body' and item 6: 'It is easy to injure your back'. The blocks represent the proportion of respondents who selected the same response options to these two items. The dashed line represents congruent beliefs (ie, the item directions are reversed). This demonstrates that the largest proportion of respondents had incongruent beliefs, that is, they believed their back to be strong (right hand side of the figure), but also easy to injure (top part of the figure).

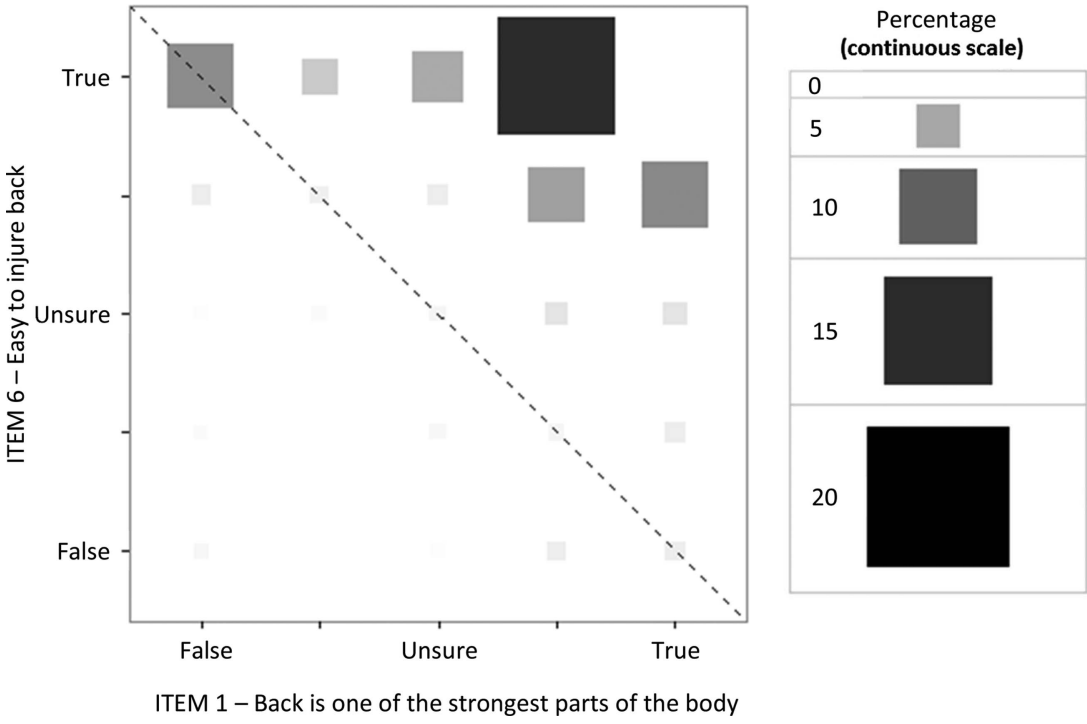

than helpful beliefs (scores closer to 1 indicate helpful beliefs, and scores closer to 5 indicate unhelpful beliefs, with 3 being unsure). The mean frequency of 'unsure' responses across all items was $12.3 \%$ (range 1.2 to 28.7; lower quartile 6.5; median 12.8; upper quartile 17.5).

\section{Subgroup analysis}

Back pain experience

The association between back pain experience and preselected items is shown in table 3. People who had current back pain had significantly higher mean scores than those who had either past or no back pain experience, for items about the ease of injuring their back (item 6; figure 3), the presence of ongoing weakness following back pain (item 32; figure 4) and the chance that back pain will not resolve (item 33; figure 5). Those with current or no back pain experience had significantly higher mean scores than those with past back pain for the item about not being able to do a lot about a back problem (item 34). Estimates of differences adjusted for age/sex/HCP exposure were not materially different from the unadjusted estimates presented in table 3 .
Figure 2 Scatter plot with density to display the correlation between item 25: 'If you have back pain you should avoid exercise' and item 26: 'When you have back pain the risks of vigorous exercise outweigh the benefits'. This demonstrates that many individuals (circa 10\%) who believed that they should not avoid exercise if they have back pain also believed that the risks of vigorous exercise outweighed the benefits (ie, top left of the figure), whereas very few believed the reverse. This indicates that although most do not believe exercise should be avoided, they still view it as being a risky behaviour.
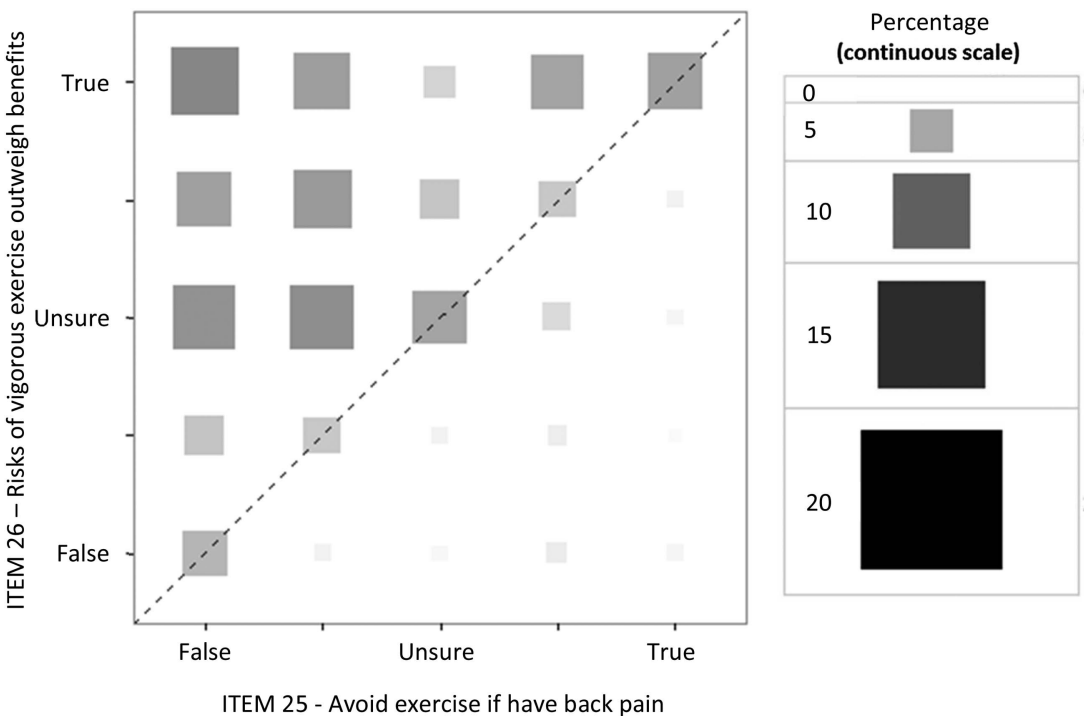
Table 3 Analysis of variance for a priori cross tabulations of individual item means by back pain experience

\begin{tabular}{|c|c|c|c|c|c|c|c|}
\hline \multirow[b]{2}{*}{ Item } & \multicolumn{3}{|c|}{ Mean by back pain experience ${ }^{*}$} & \multirow{2}{*}{$\begin{array}{l}\text { Significance } \\
\text { from analysis of } \\
\text { variance }\end{array}$} & \multicolumn{3}{|c|}{ Mean difference ( $95 \% \mathrm{Cl}$ for difference) } \\
\hline & $\begin{array}{l}\text { No LBP } \\
(n=75)\end{array}$ & $\begin{array}{l}\text { Past LBP } \\
(n=360)\end{array}$ & $\begin{array}{l}\text { Current LBP } \\
(n=162)\end{array}$ & & No vs past & No vs current & Past vs current \\
\hline $\begin{array}{l}\text { 1. Your back is one of the } \\
\text { strongest parts of your body }\end{array}$ & 4.3 & 4.0 & 3.9 & 0.070 & $0.3(-0.1$ to 0.7$)$ & $0.4(-0.0$ to 0.9$)$ & $0.1(-0.2$ to 0.4$)$ \\
\hline 6. It is easy to injure your back & 4.1 & 4.5 & 4.6 & 0.000 & $-0.4(-0.7$ to -0.1$) \dagger$ & $-0.4(-0.8$ to -0.2$) \dagger$ & $-0.1(-0.3$ to 0.1$)$ \\
\hline $\begin{array}{l}\text { 11. You could injure your back if } \\
\text { you are not careful }\end{array}$ & 4.6 & 4.6 & 4.8 & 0.032 & $0.0(-0.2$ to 0.2 & $-0.2(-0.4$ to 0.0$)$ & $-0.2(-0.3$ to -0.0$) \dagger$ \\
\hline $\begin{array}{l}\text { 22. If you ignore back pain, you } \\
\text { may cause damage to your back }\end{array}$ & 4.3 & 4.4 & 4.5 & 0.232 & $-0.1(-0.4$ to 0.1$)$ & $-0.2(-0.4$ to 0.1$)$ & $-0.1(-0.2$ to 0.2$)$ \\
\hline $\begin{array}{l}\text { 28. Most back pain settles quickly, } \\
\text { at least enough to get on with } \\
\text { normal activities }\end{array}$ & 3.7 & 3.7 & 3.6 & 0.582 & $0.0(-0.3$ to 0.4$)$ & $0.1(-0.3$ to 0.5$)$ & $0.1(-0.2$ to 0.4$)$ \\
\hline $\begin{array}{l}\text { 32. Once you have had back pain } \\
\text { there is always a weakness }\end{array}$ & 3.2 & 3.2 & 3.7 & 0.000 & $0.0(-0.4$ to 0.4$)$ & $-0.5(-0.9$ to -0.1$) \dagger$ & $-0.5(-0.8$ to -0.0$) \dagger$ \\
\hline $\begin{array}{l}\text { 33. There is a high chance that an } \\
\text { episode of back pain will not } \\
\text { resolve }\end{array}$ & 2.9 & 3.0 & 3.6 & 0.000 & $-0.1(-0.5$ to 0.3$)$ & $-0.7(-1.0$ to -0.2$) \dagger$ & $-0.6(-0.8$ to -0.3$) \dagger$ \\
\hline $\begin{array}{l}\text { 34. Once you have a back } \\
\text { problem, there is not a lot you can } \\
\text { do about it }\end{array}$ & 2.3 & 1.8 & 2.2 & 0.000 & $0.5(0.2$ to 0.9$) \dagger$ & $0.1(-0.3$ to 0.5$)$ & $-0.4(-0.7$ to -0.2$) \dagger$ \\
\hline
\end{tabular}


Figure 3 Response distribution by back pain history for item 6: 'It is easy to injure your back'.

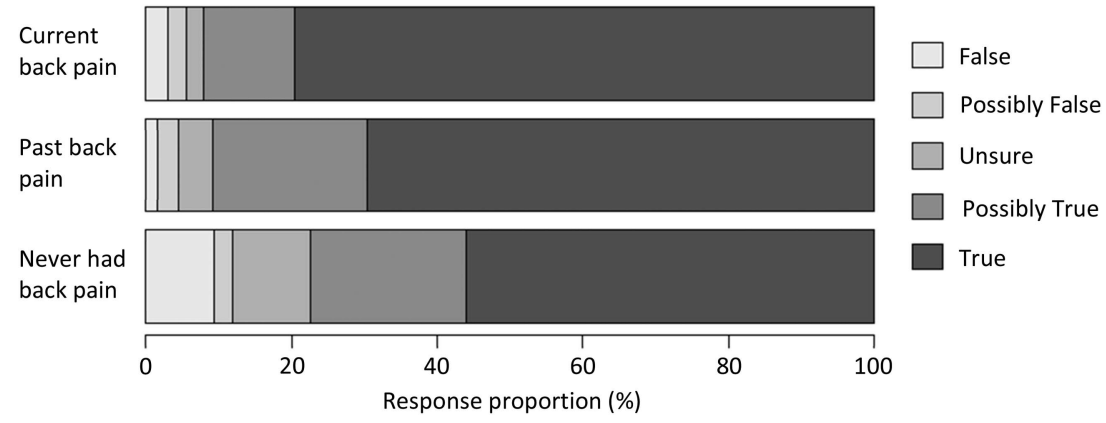

Age

There were no significant differences in the mean ages for each of the response options to item 5 about the safety of lifting without bending the knees $(p=0.17)$.

\section{DISCUSSION}

\section{Principal findings}

This survey indicates that New Zealanders generally have negative attitudes and beliefs about their backs and back pain. Respondents strongly believed that their back was easy to injure and required the protection of strong muscles, good posture, lifting technique and being careful. Respondents also viewed back pain as being special in its impact and requiring professional care.

\section{Meaning of the study}

The proportion of respondents who reported believing that the back is a strong part of the body $(76 \%)$ was very high and similar to a previous UK sample $(60 \%) .{ }^{19}$ This belief did not mean, however, that the back was seen as being difficult to injure. Two-thirds of the respondents in this study believed that their back was strong and also easy to injure. This contradiction indicates that promoting the message that the spine is strong, to either patients with back pain or the general public, may need to be rethought. This message does not seem to empower people to confidently use the back. Pre-existing beliefs that the back needs protection to prevent injury may be reinforced by experiencing back pain following a trivial injury, and may also subsequently contribute to the development of avoidant behaviour.

Overall, there was uncertainty about links between pain and injury. Over half of the sample believed back pain means the back is injured (57\%), and $89 \%$ believed ignoring pain could cause damage to the back. However, over half of the respondents also believed stress, and thoughts and feelings, could influence pain intensity. The proportion who believed thoughts and feelings could influence the intensity of pain $(58 \%)$ was similar to that found in Belgium $(64 \%) .{ }^{16}$ Over half of the respondents also believed worrying could negatively influence prognosis, while shifting focus away from the back and having positive expectations could improve the prognosis. Taken together, these findings suggest that many people are open to the idea that non-physical factors can influence their pain intensity and prognosis, but the presence of pain still indicates that the back is injured and should be protected.

A very high proportion of respondents believed they should stay active when they have back pain $(80 \%)$; this is much higher than the proportions found to hold the same belief in Canada before $(56 \%)$ and after $(63 \%)$ a 3-year mass media campaign. ${ }^{17}{ }^{34}$ This may reflect cultural differences in beliefs, ${ }^{16}{ }^{35}$ different messages being delivered by health professionals in each country, beliefs about activity changing in a helpful direction over time, ACC's advertising in NZ influencing beliefs more effectively or other factors. Regardless, there was less certainty about how active to be. Many respondents thought they should take it easy while they have back pain $(69 \%)$; this is similar to the $77 \%$ who agreed with the same statement in Belgium, ${ }^{16}$ but in contrast to $26 \%$ in a Norwegian sample. ${ }^{18}$ Vigorous activity was also viewed negatively, and a substantial minority (25\%) believed exercise should be avoided; this figure is the same as in a UK sample. ${ }^{19}$ This may demonstrate that the generic
Figure 4 Response distribution by back pain history for item 32 : 'Once you have had back pain there is always a weakness'.

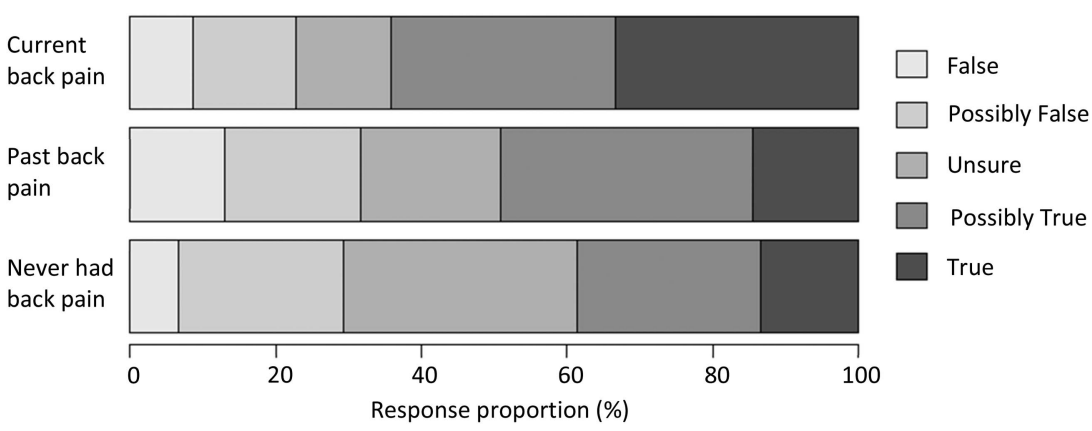


Figure 5 Response distribution by back pain history for item 33: 'There is a high chance that an episode of back pain will not resolve'.

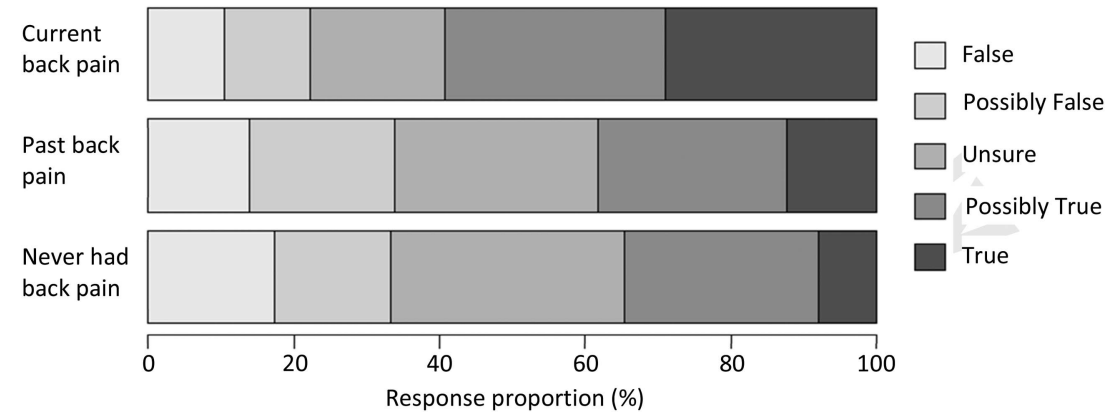

message 'be active' has been received by a majority of New Zealanders, but there is less understanding about the safety of activity and exactly what form this should take. Encouragingly, respondents who had seen an HCP for back pain had more positive views about activity than those who had not.

This sample was positive about the general prognosis for back pain, with $64 \%$ agreeing that most pain settles quickly; this compares with $44 \%$ in the UK. ${ }^{19}$ However, only $29 \%$ of the sample did not believe there would be permanent weakness following an episode of back pain (ie, the majority were unsure or believed there would be a residual weakness); this is similar to findings in an Australian sample $(22 \%) .{ }^{30}$ The belief that back pain results in ongoing weakness is likely to result in more back protection and avoidance, as well as altered appraisals of future back pain. ${ }^{22}$ This may be a key belief for HCPs to discuss with their patients.

Respondents with current back pain generally had more negative views than other respondents. In particular, they were more likely to report that the back was vulnerable and have negative views about the prognosis of back pain. Although these findings are statistically significant, it is not known if the differences in scores between groups are clinically relevant. This finding may be of clinical interest, given that low recovery expectations have a negative influence on outcome. ${ }^{14}$ Other studies have also found that people with current back pain have more negative views than those with previous pain. ${ }^{1617}{ }^{20}$ It has been suggested that recovering from back pain involves an active process whereby misconceptions are corrected. ${ }^{16}$ It makes sense that people would have more positive views about recovery if they had already found recovery to be possible.
The relationship between age and lifting beliefs was investigated because older participants in the qualitative interviews during instrument development frequently referred to the 'Don't use your back like a crane' message promoted by the ACC in the late 1980s, phrase. Current results demonstrate that although younger people may not articulate their belief in this way, they are similarly concerned about the dangers of lifting without bending the knees. This survey suggests that New Zealanders are being much more careful about lifting than they perhaps need to be, given that there is strong evidence that interventions to alter an individual's lifting technique or decrease lifting load have no impact on LBP incidence. ${ }^{36} 37$

\section{Strengths and limitations}

This study had a large sample size and a good response rate for a postal survey on a randomly selected sample from the general population. The sample was representative of the target population; in comparison with the 2013 NZ Census data, ${ }^{38}$ the sample was slightly older (census mean for those over $18=47$ years) and had a slightly higher proportion of women (census proportion $51 \%)$. NZ European, Māori and Asian ethnic groups were represented proportionally to the NZ population (census proportions $74 \%, 15 \%$ and $12 \%$, respectively). Under-representation of Māori on the Electoral Roll was effectively corrected by sampling respondents from the Māori Electoral Roll in proportion with the NZ population. Pacific Peoples were the only major population group to be under-represented (census proportion $7 \%$ ). Consequently, these data have high generalisability within the NZ population. whereas younger participants did not mention this
Figure 6 Response distribution by healthcare professional (HCP) exposure for item 27: 'If you have back pain you should try to stay active'.

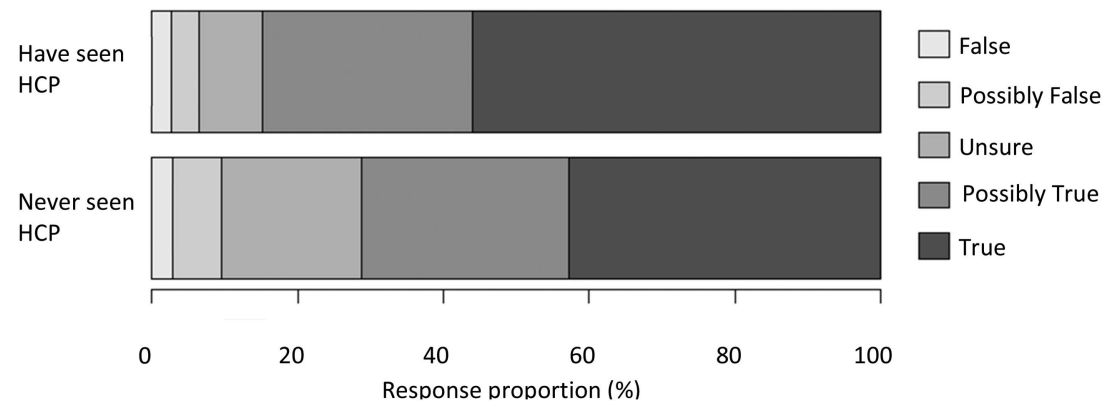


Overall, there were very low levels of uncertainty in response to Back-PAQ items, and very little missing data, suggesting that respondents understood the items, and the response options were sufficient for respondents to feel comfortable making a selection. In contrast, uncertainty when responding to the Back Beliefs Questionnaire has been reported as being between $25 \%$ and $35 \%$ for each item. ${ }^{17}$

The sampling frame employed failed to select those within the target population who had not registered on the Electoral Roll ( $<10 \%$ of target population). Young people are assumed to be under-represented on the role, as are Māori because of their younger population demographic. ${ }^{26} \quad 27 \quad 39$ This may explain why the sample was slightly older than the national average. The small difference in age is unlikely to have affected conclusions; a priori analysis of lifting beliefs did not demonstrate significant age-related differences, and adjusting for age did not alter mean differences for other a priori analyses.

The limited number of respondents who had not experienced back pain generally resulted in inadequate power to demonstrate differences between their beliefs and those of people who had experienced back pain (past or current). It is possible that those who have not had back pain are less likely to respond to a survey about back pain, and as such the prevalence figures may be inflated. However, the prevalence reported is similar to that in previous population surveys. ${ }^{17} 30$

\section{Possible explanations for findings}

This survey did not differentiate between those who were experiencing acute pain and those who had chronic symptoms. If a large proportion of respondents reporting current pain had chronic back pain, their negative prognostic beliefs may have been informed by experience of not recovering. However, the prevalence of chronic back pain in NZ has previously been reported to be only $4 \%$. $^{40}$

This survey did not demonstrate significant differences between the views of those who had and those who had not consulted HCPs, with the exception of more positive views about activity in the former group. This is in contrast to a previous systematic review which found strong evidence that HCP professional beliefs are associated with those of their patients, ${ }^{41}$ and qualitative research which found that HCPs have a strong influence on their patients' beliefs. ${ }^{22}$ This survey was not specifically designed to investigate such an association, as it made no attempt to capture which HCPs had been consulted, or to record the beliefs of the HCPs whom the respondents had consulted. Heterogeneity among HCPs to whom the respondents had been exposed could result in influences of variable direction, and subsequently no consistent association in the current analysis. The positive association between HCP exposure and views about activity may suggest that HCPs are promoting guidelines to be active during an episode of $\mathrm{LBP}^{42}$

\section{CONCLUSIONS}

This survey indicates that New Zealanders generally have negative views about the back and back pain, particularly with regard to the need to protect the back to avoid injury, and the special nature of back pain. It also suggests that there is uncertainty about how pain relates to injury. Although many hold positive beliefs about continuing to be active during an episode of back pain, there was uncertainty about what constitutes a safe or appropriate level of activity during an episode of back pain. Respondents with current back pain had more negative views about prognosis; this suggests that patients experiencing pain may benefit from targeted information about the positive prognosis. The beliefs of New Zealanders appear to be broadly similar to those of other Western populations. Consequently, the findings of this survey may also be of relevance outside of New Zealand.

\section{Author affiliations}

${ }^{1}$ Department of Primary Health Care and General Practice, University of Otago, Wellington, New Zealand

${ }^{2}$ Centre for Health Activity and Rehabilitation Research, School of Physiotherapy, University of Otago, Dunedin, New Zealand

${ }^{3}$ Biostatistical Group, University of Otago, Wellington, New Zealand

${ }^{4}$ Department of Psychological Medicine, University of Otago, Wellington, New Zealand

${ }^{5}$ Centre for Health Sciences, School of Health Professions, Zurich University of Applied Sciences, Winterthur, Switzerland

Acknowledgements The authors are grateful to Chris Almario from the New Zealand Electoral Commission for extracting the names of all registered voters from the Electoral Roll, and to Matthew Hunt for generating the random sample.

Contributors BD, MP, JS, FM, MM, GDB and AD were involved in the design of the study. BD and JS prepared and cleaned the data and also did the statistical analysis. BD wrote the first draft. All authors helped revise the paper. BD is the guarantor.

Funding This study received funding from the Physiotherapy New Zealand Scholarship Trust and from Lotteries Health Research.

\section{Competing interests None.}

Ethics approval This study was approved by the University of Otago Ethics Committee (D12/255).

Provenance and peer review Not commissioned; externally peer reviewed.

Data sharing statement The full data set can be obtained by emailing ben. darlow@otago.ac.nz.

Open Access This is an Open Access article distributed in accordance with the Creative Commons Attribution Non Commercial (CC BY-NC 3.0) license, which permits others to distribute, remix, adapt, build upon this work noncommercially, and license their derivative works on different terms, provided the original work is properly cited and the use is non-commercial. See: http:// creativecommons.org/licenses/by-nc/3.0/

\section{REFERENCES}

1. Hoy D, Bain C, Williams G, et al. A systematic review of the global prevalence of low back pain. Arthritis Rheum 2012;64:2028-37.

2. Ministry of Health. Health loss in New Zealand: a report from the New Zealand Burden of Diseases, Injuries and Risk Factors Study, 2006-2016. Wellington, New Zealand: Ministry of Health, 2013.

3. Accident Compensation Corporation. Injury Statistics Tool. Secondary Injury Statistics Tool. 31 August 2013. http://www.acc.co. nz/about-acc/statistics/injury-statistics/index.htm

4. Maniadakis N, Gray A. The economic burden of back pain in the UK. Pain 2000;84:95-103. 
5. Dagenais S, Caro J, Haldeman S. A systematic review of low back pain cost of illness studies in the United States and internationally. Spine J 2008;8:8-20.

6. van Tulder MW, Koes BW, et al. A cost-of-illness study of back pain in the Netherlands. Pain 1995;62:233-40.

7. Wieser S, Horisberger B, Schmidhauser S, et al. Cost of low back pain in Switzerland in 2005. Eur J Health Econ 2011;12:455-67.

8. Balague $F$, Mannion AF, Pellise $F$, et al. Non-specific low back pain. Lancet 2012;379:482-91.

9. Croft PR, Macfarlane GJ, Papageorgiou AC, et al. Outcome of low back pain in general practice: a prospective study. $B M J$ 1998;316:1356-9.

10. Henschke N, Maher CG, Refshauge KM, et al. Prognosis in patients with recent onset low back pain in Australian primary care: inception cohort study. BMJ 2008;337:a171.

11. Linton SJ. A review of psychological risk factors in back and neck pain. Spine 2000;25:1148-56.

12. Delitto A, George SZ, Van Dillen LR, et al. Low back pain. J Orthop Sports Phys Ther 2012;42:A1-A57.

13. Ramond A, Bouton C, Richard I, et al. Psychosocial risk factors for chronic low back pain in primary care-a systematic review. Fam Pract 2011;28:12-21.

14. Iles RA, Davidson M, Taylor NF, et al. Systematic review of the ability of recovery expectations to predict outcomes in non-chronic non-specific low back pain. J Occup Rehabil 2009;19:25-40.

15. Buchbinder R, Jolley D, Wyatt M. Population based intervention to change back pain beliefs and disability: three part evaluation. $B M J$ 2001;322:1516-20.

16. Goubert L, Crombez G, De Bourdeaudhuij I. Low back pain, disability and back pain myths in a community sample: prevalence and interrelationships. Eur J Pain 2004;8:385-94.

17. Gross DP, Ferrari R, Russell AS, et al. A population-based survey of back pain beliefs in Canada. Spine 2006;31:2142-5.

18. Ihlebaek C, Eriksen HR. Are the 'myths' of low back pain alive in the general Norwegian population? Scand J Public Health 2003;31:395-8.

19. Klaber Moffett JA, Newbronner E, Waddell G, et al. Public perceptions about low back pain and its management: a gap between expectations and reality? Health Expect 2000;3:161-8.

20. Buchbinder R, Jolley D, Wyatt M. 2001 Volvo award winner in clinical studies: effects of a media campaign on back pain beliefs and its potential influence on management of low back pain in general practice. Spine 2001;26:2535-42.

21. Waddell G, O'Connor M, Boorman S, et al. Working backs Scotland: a public and professional health education campaign for back pain. Spine 2007;32:2139-43.

22. Darlow B, Dowell A, Baxter GD, et al. The enduring impact of what clinicians say to people with low back pain. Ann Fam Med 2013;11:527-34.

23. Darlow B, Perry M, Mathieson F, et al. The development and exploratory analysis of the Back Pain Attitudes Questionnaire (BackPAQ). BMJ Open 2014;4:e005251.
24. Electoral Commission. Enrolment statistics by electorate. Secondary Enrolment statistics by electorate. 2013. http://www.elections.org.nz/ research-statistics/enrolment-statistics-electorate

25. Bowey-Morris J, Davis S, Purcell-Jones G, et al. Beliefs about back pain: results of a population survey of working age adults. Clin $J$ Pain 2011;27:214-24

26. Fitzgerald E, Stevenson B, Tapiata J. Maori Electoral Participation. Wellington, New Zealand: Electoral Commission. 2007.

27. UMR Research. Maori Electoral Engagement - a review of exisiting data. Wellington, New Zealand: Electoral Commission, 2006.

28. Statistics New Zealand. Maori-pop-estimate-MYE31Dec9111FINAL. Wellington, New Zealand: Statistics New Zealand, 2011.

29. Paine SJ, Gander PH, Harris RB, et al. Prevalence and consequences of insomnia in New Zealand: disparities between Maori and non-Maori. Aust N Z J Public Health 2005; 29:22-8

30. Buchbinder R, Jolley D. Effects of a media campaign on back beliefs is sustained 3 years after its cessation. Spine 2005;30:1323-30.

31. Asch DA, Jedrziewski MK, Christakis NA. Response rates to mail surveys published in medical journals. J Clin Epidemiol 1997;50:1129-36

32. Edwards P, Cooper R, Roberts I, et al. Meta-analysis of randomised trials of monetary incentives and response to mailed questionnaires. $J$ Epidemiol Community Health 2005;59:987-99.

33. Armitage P, Berry G, Matthews J. Statistical methods in medical research. 4th edn. Wiley-Blackwell, 2002.

34. Gross DP, Russell AS, Ferrari R, et al. Evaluation of a Canadian back pain mass media campaign. Spine 2010;35:906-13.

35. Schulz PJ, Hartung U, Riva S. Causes, coping, and culture: a comparative survey study on representation of back pain in three Swiss language regions. PLoS ONE 2013;8:e78029.

36. Verbeek JH, Martimo KP, Karppinen J, et al. Manual material handling advice and assistive devices for preventing and treating back pain in workers. Cochrane Database Syst Rev 2011;(6): CD005958.

37. Bigos SJ, Holland J, Holland C, et al. High-quality controlled trials on preventing episodes of back problems: systematic literature review in working-age adults. Spine J 2009;9:147-68.

38. Statistics New Zealand. 2013 QuickStats about national highlights. Wellington, New Zealand: Statistics New Zealand, 2013.

39. Statistics New Zealand. Enrolment statistics by electorate. Secondary Enrolment statistics by electorate. 2013. http://www. elections.org.nz/research-statistics/enrolment-statistics-electorate

40. Dominick C, Blyth F, Nicholas M. Patterns of chronic pain in the New Zealand population. N Z Med J 2011;124:63-76.

41. Darlow B, Fullen BM, Dean S, et al. The association between health care professional attitudes and beliefs and the attitudes and beliefs, clinical management, and outcomes of patients with low back pain: a systematic review. Eur J Pain 2012;16:3-17.

42. New Zealand Guidelines Group. New Zealand acute low back pain guide. Wellington, New Zealand: Accident Compensation Corportation, 2004 